\title{
INFANT FEEDING PRACTICES AMONG MOTHERS \\ OF HIGH AND LOW SOCIO-ECONOMIC GROUP \\ IN SELECTED AREAS OF DHAKA CITY
}

\author{
Momena Khatun ${ }^{1}$, Shireen Ayesha Siddiqua ${ }^{2}$
}

\begin{abstract}
Objectives: To study the patterns of infant feeding practice among the mothers of high and low socio-economic groups.

Design: The descriptive cross-sectional study was conducted among a cross section of mothers with infant of high socioeconomic group, the residents of Sobhanbag government colony \& Panthopath Green road residential area and low socioeconomic group slum area of Raver bazar, Dhaka. The study was carried out during the period of October '2007 to Mav '2008. Results: Total 104 children, $41.3 \%$ were in 9 months or more age and of them $40.3 \%$ were in high socioeconomic group \& $42.3 \%$ were in low socioeconomic group. About 96.2\% mothers from high socio-economic group provide either fullv or partiallv correct answer to the question regarding the benefit of colostrums and 59.7\% from lowsocio-economic group. Again, among the mothers from high socioeconomic groups $90.4 \%$ and $61.5 \%$ stated fully or partiallv correct answer about the benefits of breast feeding \& the optimum weaning time respectively. Colostrums intake practice was observed $94.2 \%$ mothers of high socio-economic group and $67.3 \%$ of low of socioeconomic group. Breast milk as the first food to their babies was given $71.2 \%$ mothers of high \& $65.4 \%$ of low socioeconomic group. The rate of exclusive breast feeding among mothers of 2-3 months baby from high socio-economic group was found $41.2 \%$ and low socio-economic group $34.4 \%$.
\end{abstract}

Conclusion: From this study it was evident that mothers of low socioeconomic group have poor knowledge regarding the infant feeding practices. So, Breast feeding campaign should he directed to the low socioeconomic group bv more effective wav. Strengthening of breastfeeding counseling at primarv health care center in both rural and urban area can play significant role in this regard.

\section{Key wards: Infant, Feeding Practice, High and low socioeconomic group.}

\section{Introduction}

Breast milk is the ideal food for all infants provides adequate nutritional requirements up to the age of 5 months. Breast-feeding provides them with infective agents, balanced nutrition, psychological benefits and contraceptive effects for the mother. ${ }^{1,2}$ Artificial feeding with cow's milk, goat's milk, tin milk and others has been increasing in the recent year and breast-feeding is proportionally decreasing all over the world. This is alarmingly high in developed countries. Breast-feeding is one of the three main plans of child nutrition; the others are nutrition of the mother and additional food for the infant from five months.

1. Dr. Momena Khatun. Assistant Professor, Department of Community Medicine. Shaheed Suhrawardy Medical College, Sher-e-Bangla Nagar. Dhaka.

2. Dr. Shireen Ayesha Siddiqua. Professor, Department of Community Medicine. NIPSOM, Dhaka.

Correspondence :

Dr. Momena Khatun. Assistant Professor. Department of Community

Medicine. Shaheed Suhrawardy Medical College, Sher-e-Bangla Nagar.

Dhaka.
Cell No. 01552308233. E-mail : momena khatunfehot mail.com

Recommendation of infant feed up based on current knowledge call for exclusive breast feeding for the first four to six months life followed by introducing of supplements and continuation of breast feeding for a year or longer ${ }^{3}$. In a recent completed study in Dhaka in the fully motivated mothers, exclusive breast feeding is found to provide optimum nutrition up to 5 months of infant life $^{4}$. It is generally held that breast feeding is universally practiced by rural mothers of the developing countries 5 . Traditionally Bangladesh is a breast feeding country. On the other hand there is evidence that practice of breastfeeding has declined worldwide since 1930's particularly in developed countries ${ }^{6,7}$. Breastfeeding provide natural immunity to the infants and protect them from many infectious diseases. Gastrointestinal disorder and respiratory infections are less common in breast fed infants. Talukder etal (1992) observed that inadequate breast-feeding was responsible for most of the urban poor children admitted with protein-energy malnutrition ${ }^{8}$.

Immunization saves millions of lives and requires a cold chain of vaccines for its success. Breast feeding also saves millions of lives and requires what way be termed a 'warm chain' of support for its success. The thinks in this 
'warm chain' are political commitment, knowledge and skill of the professionals strengthing of on going program for the protection and promotion of breast feeding and ultimately providing mothers the supportive care and counseling that are the key to successful breast feeding. Policy makers and the health professional need to be convinced the resources spent on 'warm chain' will pay rich dividends for our future generations ${ }^{9}$.

\section{Material and Methods.}

The study was a cross-sectional type of descriptive study. It was carried out among a cross section of mothers with infant of high and low socioeconomic group. The residents of Sobhanbag government colony \& Panthopath, Green road residential area of Dhaka were considered as high socioeconomic group and slum area of Rayer bazar, Dhaka as low socioeconomic group. The study was conducted during the period of October '2007 to May '2008. Mothers having children of age 2 months to 12 months residing in a high socioeconomic area and slum of Dhaka city were included in the study.

Total numbers of one hundred four (104) mothers were selected for collection of data, in considering time and facilities. Among them 52 were from high socioeconomic group and another 52 from low socioeconomic group. Data were collected from the mothers by face to face interview using a pre-tested questionnaire. Data were collected on sociodemographic characteristics, information related to mothers' knowledge regarding infant feeding and information about the infant feeding practices. After collection of data, all the questionnaires were checked and edited manually by the researcher herself for obvious discrepancies, aiming to reduce error. Then the data were entered into the computer using EPI info software and analysis were carried out using the SPSS program.. Frequency tables were made keeping in mind the study objectives. The Chi squaere tests were done during comparison knowledge of mothers of infant feeding practices among low and high socioeconomic groups.

\section{Results}

Socio-economic characteristics of respondents Table 1 shows the socio-demographic characteristics of 104 children of the high and low socioeconomic groups. The children selected from both low and high socioeconomic group was almost similar in age. The proportion of male children among high and low socio-economic group were $46.2 \%$ and $57.7 \%$ respectively. The literacy rate among mothers was significantly different among two groups. None of the mother of high socio-economic group was illiterate, however, $69.6 \%$ mothers of low-socio-economic group were illiterate. Of the total 104 mothers, 86(82.7\%) reported that they had been mainly engaged in household works; the proportion of housewife among high and low socio-economic groups were $88.5 \%$ and $76.9 \%$ respectively. Knowledge of mothers about infant feedings Mothers of both high and low socio-economic groups were

Table-1: Socio-demographic characteristics of respondent

\begin{tabular}{|c|c|c|c|}
\hline \multirow[t]{2}{*}{ Characteristics } & \multicolumn{2}{|c|}{ Socio-economic status } & \multirow{2}{*}{$\begin{array}{ll}\text { All } & \text { No } \\
(\%) & \end{array}$} \\
\hline & $\begin{array}{l}\text { High }(\mathrm{n}=52) \\
\text { No }\left({ }^{\circ} \mathrm{o}\right)\end{array}$ & $\begin{array}{l}\text { Low }(n=52) \\
\text { No }(\%)\end{array}$ & \\
\hline \multicolumn{4}{|c|}{ Age of the Children(in months) } \\
\hline Up to 2 & $3(5.8)$ & $1(1.9)$ & $4(3.8)$ \\
\hline $3-5$ & $11(21.2)$ & 12(23.1) & $23(22.2)$ \\
\hline $6-8$ & 17(32.7) & 17(32.7) & 34 (32.7) \\
\hline $9+$ & 21 (40.3) & $22(42.3)$ & 43(41.3) \\
\hline \multicolumn{4}{|l|}{ Sex of the Children } \\
\hline Male & $24(46.2)$ & $30(57.7)$ & 54(51.9) \\
\hline Female & 28(53.8) & $22(42.3)$ & $50(48.1)$ \\
\hline \multicolumn{4}{|c|}{ Monthly income (In Taka) } \\
\hline Up to 2000 & & $14(26.9)$ & $14(13.5)$ \\
\hline $2001-3000$ & & 31 (59.6) & 31 (29.8) \\
\hline $3001-4000$ & & $7(13.5)$ & 7(6.7) \\
\hline $10000-20000$ & $36(69)$ & & $36(34.6)$ \\
\hline $20001-30000$ & $15(28.9)$ & & 15 (14.4) \\
\hline $30000+$ & $1(1.9)$ & & $1(1.0)$ \\
\hline \multicolumn{4}{|c|}{ Education level of mother } \\
\hline Literate & & $36(69.2)$ & $36(34.6)$ \\
\hline Primary $(\mathrm{l}-\mathrm{V})$ & & $16(30.8)$ & $16(15.4)$ \\
\hline Secondary(Vl-X) & 31 (59.6) & & $31(29.8)$ \\
\hline SSC or above & $21(40.4)$ & & $21(20.2)$ \\
\hline \multicolumn{4}{|c|}{ Occupation of mother } \\
\hline House-wife & $46(88.5)$ & 40(76.9) & $86(82.7)$ \\
\hline Service holder & 6(11.5) & & 6(5.7) \\
\hline Maid servant & & $11(21.2)$ & $11(10.6)$ \\
\hline Garments worker & & $1(1.9)$ & $1(1.0)$ \\
\hline
\end{tabular}

asked some key questions regarding the infant feeding and answers were evaluated as partially correct, fully correct, and incorrect. Table 2 describes the knowledge level of mothers on the various aspect of infant feedings. Of the total, $96.2 \%$ mothers from high socio-economic group provide either fully or partially correct answer to 
the question regarding the benefit of colostrums, which is significantly higher $(p<.001)$ than that of mothers from low-socio-economic group (59.7\%). Again, among the mothers from high socioeconomic groups, $90.4 \%$ and $61.5 \%$ stated fully or partially correct answer about the benefits of breast feeding \& the optimum weaning time respectively, the proportion of which among mothers of low socioeconomic groups were $73.1 \%$ and $26.9 \%$. the differences were statistically significant (p value 0.02 and <0.001). Infant feeding pattern Colostrums intake was found almost universal (94.2\%) among mothers of high

Table-2 : Distribution of mothers regarding their correct and partial knowledge about infant feeding

\begin{tabular}{|l|l|l|l|}
\hline Variables & Socio-economic status & Significance level \\
\hline & High $(\mathrm{n}=52)$ No \% & Low $(\mathrm{n}=52)$ No \% & $\mathrm{p}$ value \\
\hline Benefits of colostrums & $50(96.2)$ & $31(59.7)$ & $\mathrm{A}^{2}=20.15 . \mathrm{p}<0.001$ \\
\hline Benefits of breast feeding & $47(90.4)$ & $38(73.1)$ & $\mathrm{A}-=5.22, \mathrm{p}=0.02$ \\
\hline Optimum weaning time & $32(61.5)$ & $14(26.9)$ & $. \mathrm{v}^{:}=12.63, \mathrm{p}<0.001$ \\
\hline Types of weaning food & $17(32.7)$ & $4(7.7)$ & $. \mathrm{v}^{:}=10.08 . \mathrm{p}=0.001$ \\
\hline
\end{tabular}

Table-3: Infant Feeding Pattern

\begin{tabular}{|l|l|l|l|}
\hline Variables & \multicolumn{2}{|l|}{ Socio-economic status } & Significance level \\
\hline & High (n=52) No \% & Low(n=52) No\% & p value \\
\hline Benefits of colostrums & $49(94.2)$ & $35(67.3)$ & $. \mathrm{v}^{:}=12.13 \mathrm{p}<0.001$ \\
\hline Benefits of breast feeding & $37(71.2)$ & $34(65.4)$ & $\mathrm{A}^{:}=0.40 . \mathrm{p}=0.52$ \\
\hline Optimum weaning time & $19(36.5)$ & $29(55.8)$ &, $\mathrm{v}^{:}=3.87 . \mathrm{pO} .00 \mathrm{O}$ \\
\hline Types of weaning food & $38(73.1)$ & $36(69.2)$ & $. \mathrm{V}^{2}=0.19 . \mathrm{p}=0.001$ \\
\hline
\end{tabular}

socio-economic group; however, significantly lower rate of colostrums intake practice was observed among mothers of low of socioeconomic group (67.3\%). Breast milk as the first food to their babies was given $71.2 \%$ mothers of high \& $65.4 \%$ of low socioeconomic group. $73.1 \%$ mothers of high \& $62.9 \%$ of low socioeconomic group breast fed their babies within 1 hour of delivery. Exclusive Breast feeding. The mean duration of exclusive breast-feeding were 3.73 with $\mathrm{SD} \pm 1.65$ months in high socioeconomic group and 4.59 with $\mathrm{SD} \pm 1.49$ months in low socioeconomic group. Figure 1 depicts the exclusive breastfeeding rate by the age of the baby. The rate of exclusive breast feeding among mothers of 2-3 months baby from high socio-economic group was found higher than that of low socio-economic group (41.2\% vs $34.4 \%$ ). However, mothers of 6-8 months baby from high socio-economic group reported lower rate of exclusive breastfeeding than that of low-socio economic groups.

Figure 1: Rate of Exclusive Breastfeeding by age group

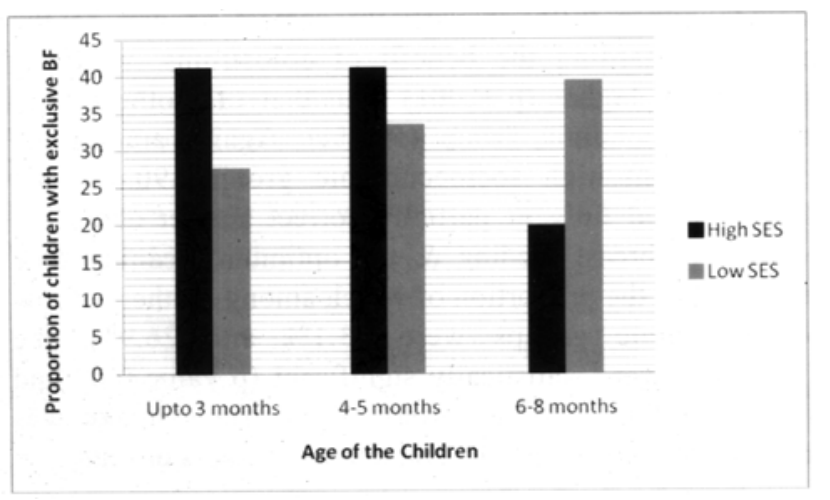

\section{Discussion}

In this cross-sectional type of descriptive study an attempt has been made to compare the breast feeding practices in high \& low socioeconomic group of people in a selected area of Dhaka city. The general objective of this study was to determine the patterns of feeding practices of mothers \& to assess their knowledge regarding infant feeding. The survey was conducted in the residential area of Sobhanbag Govt. Colony \& Panthopath, Green Road for high socioeconomic group \& Rayer Bazar slum area for low socioeconomic group. Mothers having children of age 2 months to 12 months residing in a high socioeconomic area and slum of Dhaka city were included in the study. This descriptive method is useful for identifying in infant feeding problems in different groups of peoples within time and money constrains. It is also observed that the bulk group of children was 9 to 12 months in both groups of which $40.3 \%$ constitutes of high socioeconomic group and $42.3 \%$ of low socioeconomic 
group.The study reveals that none of the mother of high socio-economic group was illiterate, however, $69.6 \%$ mothers of low-socio-economic group were illiterate. This finding supported by the fact that there is very scarce illiteracy among high socioeconomic group in Bangladesh. This is inconsistent with several other studies ${ }^{5,8,15}$. The probable cause may be due to the fact that those are old studies and educational status of women is increasing day by day. In the present study $88.5 \%$ of respondents were housewives and the rest $11.5 \%$ were service holder in high socioeconomic group. Most of the mothers of low socioeconomic group were housewives and the rest were engaged in any kind of activity other than household. The finding is consistent with several other Studies $^{5,11}$. 96.2\% mothers from high socio-economic group provide either fully or partially correct answer to the question regarding the benefit of colostrums, which is significantly higher $(\mathrm{p}<.001)$ than that of mothers from low-socio-economic group (59.7\%). It is very crucial findings for campaign of protection and promotion of breast feeding. The findings of this study suggested that $94.2 \%$ mother of high socioeconomic group \& $67.3 \%$ of low socioeconomic group gave colostrum to their babies. The difference was not statistically significant. However the overall proportion of colostrums intake is much higher than the other studies. In the present study, $71.2 \%$ mothers of high socioeconomic group \& $65.4 \%$ mothers of low socioeconomic group gave breast milk as a first food. Chaklader $^{10}$. in his study observed that, $54.4 \%$ of the infants were given colostrums as the first food, while Akter etal". in their study found that only $12.4 \%$ of mothers gave colostrums as the first food to their babies. This difference is mainly due to motivation of breast-feeding \& value of colostrums in the recent years. In the present study, it has been found that $73.1 \%$ mother of high and $69.2 \%$ mothers of low socioeconomic group breast fed their babies within one hour. No difference was found between the groups. This study was inconsistent with similar study done by Ullah etal ${ }^{3}$. Perhaps this inconsistency due to small sample size of this study. In rural Bangladesh breastfeeding is universal. Huffman et. $\mathrm{al}^{12}$ Khan et. al. ${ }^{13}$ showed that $100 \%$ of rural, $98 \%$ of urban poor $\& 78 \%$ of urban elite mothers breast feed their babies at birth. In the present study, the higher breast-feeding incidence among urban elite may be to result of motivation for breast-feeding in recent years. Talukder etal ${ }^{14}$ found the incidence of exclusive breastfeeding in $65.3 \%$ at birth \& only $28 \%$ at 4 months. Pandy et al. ${ }^{15}$ found the incidence of breast feeding $84.3 \%$ at birth \& $99.7 \%$ at 3 months. In the present study the incidence of exclusive breast feeding among mothers of 2-3 months baby from high socio-economic group was found higher $41.2 \%$ than that of low socio-economic group $34.4 \%$.This is mainly due to, mothers of high socioeconomic group are educated and motivated regarding the importance of breast feed their babies exclusively.Despite all these strengths of this study it suffers from some limitations.

1.The sample size was small and the findings might not reflex the actual situation of the population (study area).

2. There was limitation of time and money for which an extensive survey could not be done.

3. Socioeconomic status has been considered with the monthly income of the family. This might not reflex the actual socioeconomic status of the family.

4.The study could not evaluate all the aspects of objectives thoroughly due to time and facilities concern.

\section{Conclusion:}

The study depicts that mothers of low socioeconomic group have poor knowledge about the infant feedings. So, Breast feeding campaign should be directed to the low socioeconomic group by more effective way through strengthening of breast-feeding counseling at primary health care center in both rural and urban area. Mothers should be encouraged to put the baby to the breast immediately after birth and to initiate breast feeding.

\section{References:}

1. Islam MN. Pattern of infant feeding in Northern Bangladesh. Bangladesh Journal of Child health. 1998; 76: 31-35.

2. Darke SJ. Human milk versus cow's milk. J Human Nutri. 1976: 30: 233.

3. Ullah HN. Islam MN, Islam MA. Feeding practice in infants attending children out patient department of 1PGM\&R. Dhaka. Bangladesh Medical Journal.1987;20:3639.

4. Huq S. Khan N. Talukder MQ K. Infant feeding practice in Dhaka city. Bangladesh medical Journal. 1983: 12: 152-59.

5. Hambraeus L. Proprietary milks versus human breast milk in infant feeding. Pediat. Clin. North. Am. 1977: 24: 17.

6. Talukder V-1Q K. Infant feeding practices in Bangladesh and the recent dangerous trends towards bottle-feeding. Bangladesh Journal of Child health. 1984; 8(34): 8490.

7. Sloper KL \& Mckean JD. Factors influencing breastfeeding. Arch. Disease Childhood. 1975: 50: 165.

8.Talukder MQ K. Bangladesh Campaign for the protection and promotion of breast feeding, 1992: 16(1 2): 25-31

9. The UNICEF report on the state of Worlds children. 1982-83. 10. Chaklader H. A survey reports on breast-feeding practices behavior of lactating mothers. Bangladesh women's health coalition(BWHC). Dhaka. 1996; October:37-47.

11. Akter HH. A National Breast feeding survey to assess the breastfeeding practices in Bangladesh. Bangladesh Institute of Research for Promotion of Essential \& Reproductive Health and Technology (BIRPERHT). Dhaka, Is' edt. 1998: 10-13. 12. Huffman SL, Chowdhury AKMA. Chakraborty DJ. Breast-feeding patterns in rural Bangladesh. The American Journal of Clinical Nutrition. 1980; 33.: 144-154.

13. Khan MU. Infant feeding practice in rural'Meheran. Comilla. Bangladesh. The American Journal of Clinical Nutrition. 1980; 33: 2356.

14. Talukder MQ K \& Huq N. Breast-feeding practices in 
15. Pandey GK. Hazra S, Chatterjee F. Breast feeding indicators from rural community west Bengal. India $\mathrm{J}$ of public health. 1997 4l(3):71-74 